\title{
Training moral sensitivity through video games: a review of suitable game mechanisms
}

\author{
Katsarov, Johannes ; Christen, Markus ; Schmocker, David ; Tanner, Carmen ; Mauerhofer, Ralf
}

\begin{abstract}
The goal of this study is to support game designers in the selection and implementation of game mechanisms to promote players' moral sensitivity. A lack of moral sensitivity may lead people to behave unethically, without awareness for their actions' moral implications. In this study, we conduct a theorybased evaluation of 20 distinct game mechanisms in view of their potential to promote moral sensitivity. Moral sensitivity is thereby operationalized in terms of three learning outcomes: Empathic concern for relevant groups, alertness to values/principles, and awareness for one's vulnerability to biases. This study suggests that moral sensitivity is best promoted through a careful combination of game mechanisms, addressing all three learning outcomes.
\end{abstract}

DOI: https://doi.org/10.1177/1555412017719344

Posted at the Zurich Open Repository and Archive, University of Zurich

ZORA URL: https://doi.org/10.5167/uzh-143918

Journal Article

Accepted Version

Originally published at:

Katsarov, Johannes; Christen, Markus; Schmocker, David; Tanner, Carmen; Mauerhofer, Ralf (2019). Training moral sensitivity through video games: a review of suitable game mechanisms. Games and Culture, 14(4):344-366.

DOI: https://doi.org/10.1177/1555412017719344 
For citation:

Katsarov, J., Christen, M., Mauerhofer, R., Schmocker, D., \&

Tanner, C. (2017). Training Moral Sensitivity Through Video

Games - A Review of Suitable Game Mechanisms. Games and

Culture. https://doi.org/10.1177/1555412017719344

\title{
Training Moral Sensitivity Through Video Games - A Review of Suitable Game \\ Mechanisms
}

\author{
Johannes Katsarov, Markus Christen, David Schmocker and Carmen Tanner \\ University of Zurich \\ Ralf Mauerhofer \\ KoboldGames, Brugg, Aargau
}

April 27, 2017

\section{Author Note}

Johannes Katsarov, Center for Ethics, University of Zurich; Markus Christen, Center for Ethics \& UZH Digital Society Initiative, University of Zurich; David Schmocker, Institute of Banking \& Finance, University of Zurich; Carmen Tanner, Institute of Banking \& Finance, University of Zurich / Leadership Excellence Institute Zeppelin, Zeppelin University, Friedrichshafen; Ralf Mauerhofer, KoboldGames, Brugg, Aargau.

This research was supported by grant No. CR1111_159279/1 from the Swiss National Science Foundation.

Correspondence concerning this article should be addressed to Johannes Katsarov, Center for Ethics, Winterthurerstrasse 30, 8006 Zurich, Switzerland, johannes.katsarov@uzh.ch 


\begin{abstract}
The goal of this study is to support game designers in the selection and implementation of game mechanisms to promote players' moral sensitivity. A lack of moral sensitivity may lead people to behave unethically, without awareness for their actions' moral implications. In this study, we conduct a theory-based evaluation of 20 distinct game mechanisms in view of their potential to promote moral sensitivity. Moral sensitivity is thereby operationalized in terms of three learning outcomes: Empathic concern for relevant groups, alertness to values/principles, and awareness for one's vulnerability to biases. This study suggests that moral sensitivity is best promoted through a careful combination of game mechanisms, addressing all three learning outcomes.
\end{abstract}

Keywords: game-based learning, moral education, ethics, moral sensitivity, moral awareness 
Scientific evidence shows that video games can have positive effects on the morality and pro-social competences of players (e.g., Greitemeyer, Agthe, Turner, \& Gschwendtner, 2012) and the development of attitudes and competences more generally (Wouters, van Nimwegen, van Oostendorp, \& van der Spek, 2013). In this paper, we evaluate the potential of single game mechanisms for enhancing a specific moral competence, moral sensitivity (MS). By game mechanisms, we denote elements of a game that enable or frame the interaction of the player with the game. First, we introduce the competence of MS and elaborate, how it can be explicated in terms of three learning outcomes, which ought to guide MS-related training. Then, we describe and evaluate 20 game mechanisms, looking at whether and how they may promote the achievement of the three MS-related learning outcomes. We conclude with some considerations on the combination of relevant game mechanism to promote MS through game-based learning.

\section{Learning Outcomes for the Achievement of Moral Sensitivity}

MS can be understood as the ability of people to recognize the moral features of a given situation when they arise in practice, and to afford them importance (Jordan, 2009). Due to its reliance on multiple reflective and automatic cognitive processes (e.g., Blum, 1991), we understand MS as a competence. As pedagogical goals, competences refer to a specific type of problem or challenge, which competent people should be able to deal with effectively. From our perspective, the challenge, which shall be overcome through the competence of MS, is moral blindness. Moral blindness, failing to see or recognize a moral issue, can prevent a person from moral decisionmaking and behavior (Rest, 1986).

For training purposes, and for the evaluation of possible training strategies, a broadlydefined learning goal like the competence of MS should be broken down into more concrete 
learning outcomes. In our efforts to identify more specific learning outcomes for the training of MS, we have reviewed diverse investigations on the roots of moral blindness. ${ }^{1}$ Our review shows that one source of moral blindness is a lack of motivation to act morally. Additionally, we have identified three distinct, but interconnected perceptual sources of moral blindness. In this paper, we concentrate on these perceptual sources of moral blindness, in proposing three distinct learning outcomes for the training for MS, all of which seem indispensable to foster a high level of MS (if people are sufficiently motivated to be moral, too). To become morally sensitive, people should develop (a) an empathic concern for relevant groups, (b) alertness to values/principles, and (c) awareness for their vulnerability to biases.

\section{Empathic Concern for Relevant Groups}

Like Blum (1991), we consider mature empathy as one of the primary sources of (intrinsically motivated) moral sensitivity. Mature levels of empathic concern and affective perspective taking enable people to experience empathic distress when the wellbeing of others is affected (Decety \& Cowell, 2014). At the most mature levels, adults experience empathic distress beyond the actual situation, e.g., imagining what someone else might feel like in the future, and they become able to empathize with an entire group of people (Hoffman, 2000). Following Hoffman (2000), empathy is best promoted through induction, i.e., encouraging people to engage in perspective taking, e.g., by highlighting what others may feel, pointing to others' distress, and getting people to acknowledge when they have caused someone else's distress. Since empathy is prone to different biases and over-arousal (Gibbs, 2010), only fostering empathy is not sufficient to foster MS. A potential cure to one of these biases, the familiarity-similarity bias, may be mature

\footnotetext{
${ }^{1}$ A more detailed account of this review is work in progress.
} 
empathy itself. Whereas people tend to empathize most strongly with others, whom they know well, and who are currently present, empathy can also be induced for remote and dissimilar individuals and groups through exposure and exercises of perspective taking (Batson et al., 1997).

\section{Alertness to Values/Principles}

A person's alertness to the situational relevance of moral values and principles is the second source of MS. People with a mature alertness to values/principles appraise situations and possible actions in view of ethical values and principles, arriving at emotionally laden valuations, e.g., judging an action unfair (Tanner \& Christen, 2014). ${ }^{2}$ Depending on the magnitude of foreseeable consequences, the immediacy and proximity of effects, the moral features of situations or behaviors may be more or less salient (Jones, 1991). We therefore suggest that an important goal for the training or MS should be to sensitize people to moral values and principles in view of (complex) issues, with which they are regularly confronted. Only when moral schemas (ethical values, principles, etc.) are similarly accessible as strategic schemas (which concern self-regarding goals of individuals or organizations), will people be equally sensitive to moral features of situations and behavioral options, and recognize relevant cues (Tanner \& Christen, 2014). Two strategies, which Vandenberg and Uglietta (2015) propose for developing moral schemas and linking them to one's

${ }^{2}$ The ethical values and principles, which provoke these valuations, need to have been internalized (or constructed) to a sufficient degree, for a person to find them intrinsically motivating. We suggest that this should be a goal of training towards moral commitment, another moral competence. 
regular practices, are to contemplate upon these practices in view of moral aspects (via ethical reflection), and to witness others acting in ethically sensitive ways (via modelling).

\section{Awareness for Vulnerability to Biases}

Bazerman and Banaji (2004) suggest that we need to become aware of our vulnerability to unconscious biases, if we want to avoid moral blindness. There are many psychological biases that can affect people. For example, psychic numbing refers to the tendency of people to experience less compassion for groups of victims than for individual victims (Small, Loewenstein, \& Slovic, 2007). The status-quo bias motivates people to favor established behaviors and conditions, e.g., smoking or discriminating rules, even when there are good reasons to change them (Samuelson \& Zeckhauser, 1988). To cope with psychological biases, morally sensitive people rely on ethical principles (Gibbs, 2010) and prepare well for dealing with situations, in which they risk biased perceptions and judgments (Bazerman \& Tenbrunsel, 2011).

\section{Identification and Evaluation of Game Mechanisms}

Promoting targeted learning through video games requires a careful selection and design of game mechanisms. Numerous definitions of game mechanisms exist. We use a rather broad understanding that does not only include elements of interaction with the game per se, but also elements which frame the player's interaction with the game. Concretely, we are interested in the (1) possible actions and choices of players, (2) how these are framed (role, perspective, goals), and (3) which consequences the players' actions and choices may have (feedback, rewards, etc.).

When identifying game mechanisms, which could possibly contribute to the development of moral sensitivity (MS), we combined an inductive with a deductive approach: We reviewed five 
books and papers, which describe video games that might contribute to moral development, and searched for game mechanisms, which may be related to MS (Christen, Faller, Götz, \& Müller, 2013; Flanagan \& Nissenbaum, 2014; Ryan, Staines \& Formosa, 2016; Schrier, 2015; Staines, 2010). In addition, we discussed each of the three learning outcomes for the development of MS, and brainstormed about possible game mechanisms in our multidisciplinary and game-experienced team. The mechanisms, which we have selected, are surely not conclusive. However, they should offer the most comprehensive collection of game mechanisms for the development of MS, which has been published so far.

In the following, we assess the potential of 20 game mechanisms to promote MS. The purpose of our evaluation is to support game designers in the selection and implementation of game mechanisms to foster MS. We offer a theory-based evaluation of single game mechanisms' potentials, for this purpose. The data, which would be required to evaluate the actual effectiveness of single game mechanisms empirically, is not yet available. However, this study may support such effectiveness evaluations in the future, by offering a classification scheme for distinct game mechanisms, and a set of hypotheses concerning their ability to promote the achievement of MS.

Concretely, our assessment focuses on the questions, whether and how a distinct game mechanism might support MS-related learning, i.e., the achievement of one or more of the three learning outcomes described above. Hence, in discussing whether a game mechanism could potentially support the attainment of MS-related learning outcomes, we also formulate specific hypotheses concerning how a distinct game mechanism might support MS-related learning, and under which conditions it may or may not be helpful.

In our evaluation of game mechanisms' potentials to foster MS, we presuppose that the game mechanisms have been realized within a video game. In our understanding, a video game 
unites diverse game mechanisms, embedding them in a complex system of game mechanics and a narrative, to provide an engaging, immersive experience of gameplay. Our paper does not consider the motivational quality of how the game mechanisms are realized. In making our evaluations, we assume that the motivational quality of the relevant game mechanism is sufficiently good for a player to find the game, in which it is realized, entertaining.

We have evaluated each of the game mechanisms in an identical manner. Each mechanism is introduced individually, offering (a) its generic description, (b) an example for its implementation, and (c) an evaluation of its potential to serve the three MS-related learning outcomes (LO1, LO2 and LO3). The examples are for illustrative purposes only. The referenced games, wherein the game mechanisms have been realized, generally combine several game mechanisms: Hence, our evaluations of game mechanisms should not be misunderstood as evaluations of the games, which we refer to.

\section{Victim Perspective}

Players are victimized by the consequences of unethical behavior, which they experience through the perspective of their avatar.

Example: Life is Strange (Dontnod, 2015): Players experience unethical behaviors, e.g., being threatened, bullied, ridiculed, kidnapped, etc. in the role of a young, female photography student with limited means of self-defense.

Evaluation: Taking the role of a person, who is victimized by unethical behaviors first hand as part of a story, where the player is afforded some autonomy, promises to be what Belman and Flanagan (2010) call a high-involvement induction for the development of empathy. Batson et al. (1997) have already shown that taking the perspectives of stigmatized groups, e.g., homeless 
people, can significantly improve people's attitudes towards members of these groups. The ability of video games to foster the development of empathy is further supported by the outcomes of diverse experiments that have shown that playing an avatar fosters an identification with this character, and can have psychological effects of some duration (Ganesh, van Schie, de Lange, Thompson, \& Wigboldus, 2011; Rosenberg, Baughman, \& Bailenson, 2013). We therefore expect that in-game victim experiences of unethical behaviors may be a strong mechanism to foster empathic concern, particularly for vulnerable groups (LO1). Taking the perspective of a victim may further promote the development of one's moral principles for the evaluation of difficult situations: E.g., physically strong players, who experience the perspective of Max in Life is Strange, may realize that expecting everybody to be able to defend themselves may be asking too much (LO2).

\section{Perpetrator Perspective}

Players take the role of a person or organization who is responsible for unethical behavior, or who is strongly challenged to behave unethically to progress in the game. The focus here is on experiencing oneself in the role of a perpetrator and seeing how one's actions affect others.

Example: The McDonald's Video Game (Molleindustria, 2006): In this business simulation, players are tempted to bribe officials, cover up health risks, destroy indigenous villages etc., so to make profits, whereby they hardly have other options.

Evaluation: Flanagan and Nissenbaum (2014) argue that playing The McDonald's Video Game could create an awareness for the destructive potentials of unregulated capitalism, and sensitize players for biases like a narrow focus on goals like profit maximization. Taking a perpetrator perspective could thus nourish players' sensitivity for the need of universal, ethically 
based rules, and help players become sensitive to human biases (LO2/3). However, we suppose that only players, who are already morally sensitive to some extent, will be stimulated to reflect on such aspects in playing a perpetrator. In morally insensitive players, this mechanism might promote a one-sided understanding the perpetrator's perspective and help to rationalize unethical behaviors (Miller, Gordon, \& Buddie, 1999). We therefore expect negative effects from this mechanism in terms of empathic concern for relevant groups (LO1), if no corrective game mechanism is in place, and if players aren't yet morally sensitive. In line with our assumptions, Grizzard, Tamborini, Lewis, Wang and Prabhu (2014) have found that "players who commit moral transgression in video games actually become more sensitive to moral violations, if they feel guilt." (p. 502, emphasis added).

\section{Perspective Change}

Players experience multiple, interconnected perspectives during a game. They are thereby sensitized for the ways in which the actions and decisions in one role may affect their experience of other roles - whether these effects are intended or not.

Example: The Detail (Rival Games, 2014): Players slip into different roles in a complex criminal investigation. They enact an older detective, a young policewoman, and a former criminal, who is now a caring father and taxi driver. In each role, players make decisions, which have an impact on the other characters.

Evaluation: In-play perspective changes are probably a powerful device to foster empathic concern for different groups (LO1) and sensitize players for the relevance of moral principles or values in complex situations (LO2). At the beginning of The Detail, playing a senior detective, the player must engage a former gang member, who still owes his colleague a favor, to make progress 
on a case. The player can either ask the gang member for help in a friendly way, or coerce him and treat him badly in several dialogues. Then, without forewarning, the player goes onto playing the former criminal, and learns how the man regrets being pulled back into the world of crime, worries about his family, etc. Depending on how players treated the former gang member when playing the detective, they might feel bad about their earlier decision, and develop an empathic concern for former criminals (LO1). In similar ways, this mechanism may be used to attain all LOs relevant for MS, e.g., by giving players the opportunity to act upon biases or stereotypes, only to then be confronted with relevant consequences for the next person they play.

\section{Prosocial Challenge}

Players have goals or side-objectives, which are explicitly or implicitly ethical, e.g., to protect someone, help people, or fight injustice. They experience the opportunity (or need) to associate with characters who are suffering and understand causes and remedies, e.g., in the role of a friend, protector, or journalist.

Example: Life is Strange (Dontnod 2015): Players build friendships or alliances with victims of unethical behavior, e.g., a girl, who was drugged, filmed while kissing multiple boys, and consequently shamed publicly. In another scene, the avatar's best friend is paraplegic, and players find themselves in a situation, where they must help her, and understand her plight, hopes, etc.

Evaluation: A prosocial challenge unfolds many opportunities for the development of empathic concern, because players need to understand and help others to succeed. Where exposure to many different groups can be created, where players learn a lot about the hopes, thoughts, and feelings of other individuals, e.g., through dialogues or diaries, an empathic concern for other 
people can be nurtured (Decety \& Cowell, 2014). Where care is required, players are additionally invited to practice empathic skills (LO1). A prosocial challenge can also accustom players with ethical principles and values first hand, since they underlie the objectives of the game and are relevant for success (LO2).

\section{Negotiation}

Players engage in dialogue with non-playable character (NPCs), with the challenge of coming to an agreement on a problem with ethical dimensions.

Example: Deus Ex: Human Revolution (Eidos, 2011): Playing a security specialist in this action role-playing stealth video game, players will sometimes face difficult negotiations with NPCs. For instance, to gain access to police headquarters, players can persuade a former colleague. This colleague, however, still holds a grudge against the player's avatar, and is still mourning his killing of a young man. To persuade the policeman, the player must be very empathic in deciding among numerous dialogue options.

Evaluation: The option to retry the challenging and highly emotional dialogue through saving enables players to get a good understanding of the complex character, and practice empathic skills around a morally dilemmatic issue. We assume that this kind of a gaming challenge, when set up appropriately, can promote empathically-based MS through the need to engage in perspective-taking (LO1), and connect moral principles and values with the relevant issues through their evaluative application (LO2). Negotiation, persuasive, and deliberative activities also can sensitize players to avoid biased questions and answers, and to detect biased ideas of others (LO3). 


\section{Investigation}

Players are challenged to understand a complex case of unethical behavior. This sort of investigation may include diverse challenges, like data collection (e.g., via interviews), problem analysis, or drawing logical conclusions.

Example: L.A. Noire (Team Bondi, 2011): In this detective game, players solve a wide range of cases, searching crime scenes for clues, interrogating people, etc. When interviewing suspects, players must draw on their evidence, e.g., to confront lies.

Evaluation: Through the investigation of unethical behavior, players may be sensitized to aspects of such behaviors in the future, understand the harm done to others, as well as the perpetrator's motives and biases (LO2/3). An empathic sensitization for unethical behaviors can probably be realized through this kind of role-taking, if players are exposed to individual victims of the unethical behaviors, who come over as being authentic, and undeserving of what has happened to them (Gibbs, 2010; LO1). A detailed portrayal of unethical behaviors, their appearance, and their consequences, may help to increase the moral salience of relevant behaviors for players in the future. Drawing on insights from the psychology of attitudinal learning (e.g., Martens, 1998), the connection between perceived features of the unethical act and moral values, will probably be fostered most strongly, when positively characterized NPCs evaluate the act as morally wrong, based on relevant values (LO2). A sensitization for biases may be achieved by having the wrongdoers excuse their actions with explanations like "I never thought something like this could happen" (LO3). 


\section{Conflict Mediation}

Players are challenged to support NPCs in working out a conflict. Players do not only witness the conflict, but are also drawn into it: Their actions and decisions influence whether/how the conflict can be resolved.

Example: Façade (Procedural Arts, 2005): In this artificial-intelligence based game, players witness a couple, both close friends, in a marital dispute. Depending on the sentences, which players write to influence the couple, they can either support conflict resolution, drive the couple further apart, or be kicked out of the apartment.

Evaluation: Where conflicts bear moral aspects, challenging players to resolve them peacefully may provide a powerful game mechanism to promote MS. To resolve the conflict, players will need to understand the perspectives of the different parties, also at the emotional level (LO1). Additionally, conflicts may feature clashes of (moral) values, and can therefore be used to invoke value-/principle-based sensitivity in players, e.g., in understanding the different sides' arguments and needs, and trying to explain them to the other side (LO2). Biases are often powerful in conflicts: The player's role could include the identification and constructive confrontation of biases to cool the conflict down (LO3). However, it is questionable, whether players will learn to see biases this way, if they aren't aware of them in the first place. A remedy could be for the involved NPCs to point out each other's thinking biases at some point, if the player fails to notice them, thereby sensitizing the players (especially if they fail in their first attempt).

\section{Ethical Dilemmas}

Players are confronted with an ethical dilemma, where they must decide between several actions. Their decisions will inevitably violate a moral value. All that players can do is to choose 
the "lesser evil". Unlike a scripted approach with one-time decisions to be made, a systemic approach puts players into a complex dilemmatic situation or role, where many small decisions make a crucial difference (Stevenson, 2011).

Example: Papers, Please (Pope, 2013): In the role of an immigration officer, players are subject to repression through different parties: Their government, and a revolutionary opposition. If they do not live up to diverse expectations, some of them contradictory, they will suffer personal losses, e.g., harm to their family. They can help people in need, but only at a cost, and in danger of retaliation.

Evaluation: Dilemmas are value conflicts per definition. If they are presented well, they necessarily raise alertness to values/principles (LO2). Whether the dilemma increases empathic concern (LO1), will depend on the exact framing of the dilemma (e.g., on how the affected persons are characterized). Dilemmatic situations may be prone to bias: For instance, players could choose one option as the "lesser evil", because they are more concerned with the immediate effects, and neglect remote effects. Thus, this mechanism may promote biased deliberation, instead of reducing it (LO3). To mitigate this risk, the dilemma would need to be presented in a way, which fosters empathy for all involved parties, and which sensitizes players to the potential biases, or in combination with feedback.

\section{Egoistic Temptations}

Players are confronted with decisions, where they will suffer a strategic loss (e.g., loss of money, power, or peer appreciation), if they act morally. Players must therefore sacrifice some sort of in-game rewards or resources to do what seems morally right. 
Example: Bioshock (2K Games, 2007): Depending on whether they kill so-called "Little Sisters" or spare their lives, players of this first-person shooter game either gain a lot of magical powers, or fewer magical powers. Thus, ethical actions make it more difficult to win the game (at least in the short term: in the end, ethical action pays off, after all).

Evaluation: This mechanism includes the possible violation of moral values, and therefore fosters alertness to them (LO2). Egoistic temptations are closely linked to egoistic biases. Without any kinds of additional mechanisms, which make players aware of their biases, or which frame egoistic decisions as selfish and immoral, there is a risk that this game mechanism can desensitize players to egoistic biases (LO3). In Bioshock, a character named "Dr Tenenbaum" tries to persuade the main character to spare the Little Sister's lives, appealing to players' empathy. The characterization of the "Little Sisters" as little girls, who blindly trust the player as a "Big Daddy", may contribute to the induction of empathy, which would at least nudge players towards finding it unethical to kill the Little Sisters (LO1).

\section{Deception}

Players are deceived into misjudging other actors in the game by serving them incomplete or biased information, thereby encouraging them to treat these actors unfairly. Especially by working with people's potential stereotypes, e.g., prejudice concerning age, gender, ethnicity, sexual orientation, etc., players can be stimulated to discriminate against other players or NPCs in a positive or negative way. At some point of the game, players' stereotypes and misjudgments are then disappointed. Players become aware that they have (potentially) wronged characters in the story, and/or that they have been fooled by others, whom they should not have trusted. 
Example: Deux Ex (Ion Storm 2000): Playing the member of an anti-terrorist unit, players can either kill terrorists on their missions, or fulfil their missions peacefully (mostly by stealth). Throughout the course of the story, players become aware that they are actually fighting on the wrong side. They find out that their own organization has ruthlessly been spreading diseases for economic purposes, and switch to work with the "terrorists", whom they now recognize as freedom fighters.

Evaluation: A key characteristic of this mechanism is that players realize during the game that their biased view has led to a disadvantageous outcome. If players of Deus Ex have been merciless in killing terrorists throughout the first part of the game, they may sense a feeling of guilt after getting to know the freedom fighters better. This mechanism may be powerful in sensitizing people to the fact that they themselves can be misled and be biased in their perceptions (LO3). This way, the game mechanism could help to foster a more universal sense of empathy with all humans, independent of their side in a conflict (LO1), and lead players to apply moral principles, e.g., fairness and prudence, to the evaluation of conflict situations in the future (LO2).

\section{Action under Pressure}

Players perform tasks with ethical relevance under time or peer pressure. Pressure can be real (countdown, fast-paced (re)actions of NPCs) or symbolic (e.g., fast-paced music, reminders, criticism). This leaves less time for contemplation and may lead players to make decisions without being able to think through all potential consequences. Later in the game, players may regret their decisions, e.g., because they didn't take more time to reflect, lacked important information, or didn't protest / make up their own mind. 
Example: SWAT 4 (Irrational Games, 2005): In the role of a senior S.W.A.T. commander, players enter dangerous crime scenes, take down armed criminals, and save innocent bystanders, or hostages. Without well-planned security measures, players quickly lose control, e.g., in shootouts, thereby losing hostages or colleagues.

Evaluation: Action under pressure is likely to have a negative effect on players' empathic concern with the groups involved in a situation (LO1), to disable principle-/ and value-based sensitivity (LO2), and to get players to make biased decisions (LO3), all of which can lead to players making unethical decisions in a game (Bazerman \& Tenbrunsel, 2011). In combination with good feedback mechanisms, action under pressure can foster awareness for one's psychological biases (LO3) and help players develop an empathic concern for the possible victims of biased behaviors (LO1). To cope with these biases in agitated situations, players may then resort to ethical principles for planning how to deal with future situations, and understand the general importance of such principles in real-life situations (LO2).

\section{Modelling}

Moral (or immoral) attitudes and behaviors are modelled to players. Modelling can occur through different communication channels, e.g., via video sequences, diaries, or thinking aloud. The models can be NPCs, but also the avatar, the character whom the player plays.

Example: In the fantasy adventure game Silence (Daedalic, 2016) players switch between the roles of an adolescent brother and his little sister. Many of the actions, which players must perform, model prosocial behaviors, e.g., saving a companion's life through heart resuscitation. Players can also choose between different options regularly, which mirror competing values, e.g., 
standing up for one's little sister at the risk of being ridiculed, vs. scolding one's little sister at the risk of making her sad.

Evaluation: Positive modelling can be used to demonstrate empathic skills and behaviors to players. Similarly, negative role-models can demonstrate careless behaviors and attitudes. Research on attitudinal learning and social skills suggests that a combination of positive and negative role-models can be particularly effective in fostering constructive attitudes in people, especially when the different attitudes and behaviors are contrasted, and lead to different results (Martens, 1998). Silence illustrates two strategies, how video games can take modelling beyond the options of other media. Either by having characters enact prosocial behaviors as part of their problem-solving activities, or by giving players the opportunity to try out and compare two behavioral alternatives (along with their immediate consequences, see Game Mechanism 14). Beyond taking a prosocial perspective (Game Mechanism 4), experiencing how someone shows empathy can function as a moral exemplar: Players may learn new or refined scripts for their own empathic behavior in the future (LO1). Additionally, role-modelling can portray, and ideally contrast, behaviors that either correspond with moral values and principles, or breach them, thereby fostering cognitive MS (LO2). It is also possible to model (lack of) sensitivity to biases (LO3). On a final note, positive role-models must be framed positively, e.g., as experts, admirable peers, or heroes, and their behaviors must be successful (at least in the long run), for modeling to work (Martens, 1998). Correspondingly, negative role-models will only discourage dissociative attitudes and behaviors, if their character is called into question, and/or the results of their actions are bad. 


\section{Guidance}

Players receive guidance for their game actions, e.g., via mission briefings, via NPCs who act as their colleagues, mentors or advisors, or in form of instructions and hints, which may be delivered directly to the players through the game designers, e.g., while a new scenario is loading. Guidance can also be offered in terms of background knowledge, e.g., regarding the potential consequences of an action.

Example: In PeaceMaker (ImpactGames, 2007), players have several political advisors. Each time they face a complicated decision regarding their management of the Israeli-Palestinian conflict, their advisors will offer different, sometimes contradictory assessments of the situation.

Evaluation: The advice offered in PeaceMaker is a fine example, of how games can create awareness for the needs and perceptions of different groups (LO1), and how moral principles and values can be embedded in games, before decisions are made - thereby supporting an informed decision, and sensitizing players to the relevant values and principles (LO2). Hints and instructions can also sensitize players for possible biases, e.g., if players are warned that their decisions will also have long-term consequences (LO3). Accordingly, a study by Joeckel, Bowman and Dogruel (2012) indicates that players, who have been primed to realize that a game decision relates to ethical values, which they honor, tend to make the decision in line with their values.

\section{Direct Consequences}

Players make decisions regarding a morally loaded issue under some degree of uncertainty, and receive immediate feedback / with immediate consequences.

Example: The Witcher 3: Wild Hunt (CD Project RED, 2015): In this third-person combat game, players can investigate an arson, hired by a blacksmith, whose forge has been burnt down. 
Upon retrieving the arsonist, a drunk villager, angry at the blacksmith for working with an occupant army, the player can either take a bribe and leave the arsonist in peace, or deliver him to the blacksmith. If the player decides to force the arsonist to apologize, the blacksmith will immediately have a group of soldiers hang the arsonist.

Evaluation: Depending on how the decisions are framed, this mechanism is likely to have a positive impact on all learning outcomes. The example above is bound to induce empathic distress in some players (LO1): The arsonist confesses his guilt to the blacksmith and is obviously ashamed of what he has done. The blacksmith, on the other hand, condemns all the villagers, and - though he could spare the life of the arsonist - decides to have him killed. The grave and immediate consequences, which the player's decision has in this somewhat uncivilized context, may seem unwarranted. They may foster the sensitivity for moral values, e.g., the importance of a fair trial (LO2). Furthermore, players may become aware of how they may have been biased in the assessment of the situation through their interest in serving the blacksmith, a paying customer (LO3).

\section{Delayed Consequences}

Players are confronted with morally loaded decisions. The outcomes of each option or strategy are vague or unclear, due to chance and unforeseeable developments. Players cannot necessarily be aware of the concrete ethical implications and in-game consequences, which their game behavior may have.

Example: Black \& White (Lionhead Studios, 2001): In this simulation game, players are a tribe's god, and must look out for their people. The player can decide between diverse behaviors, which range from benevolent to gruesome. On earth, the player has a pet, which learns from its 
master. If the player tyrannizes people in the game, the pet will start to do so to, eventually, thereby creating additional problems, which the player will need to solve.

Evaluation: Delayed consequences are bound to have similar learning effects as direct consequences. However, the delay of consequences undermines the temptation of aborting the game to reload and reverse one's decision, thereby forcing players to live with the consequences of their actions (Christen et al., 2013). In the case of games that involve systemic ethical dilemmas, where different consequences emerge due to many small decisions, delayed feedback is imminent (cf. Game Mechanism 8). Formosa et al. (2016) argue that a combination of systemic dilemmas and delayed consequences is powerful in promoting MS. Delayed consequences may help confronting biases towards short-term thinking, e.g., when players opt for quick-and-easy strategies, which provide positive results immediately, but finally result in highly negative consequences (LO3). They may also be helpful to challenge players to identify adequate ethical principles, e.g., for dealing with situations, where doing small favors for relatives may seem like the right thing to do, but puts many other people at an unfair disadvantage overall (LO2). For this mechanism to foster empathy, the consequences will need to be emotionalized, though, e.g., through harm to significant NPCs (LO1).

\section{Real-World Facts}

After players behave in a certain way during a game, they are confronted with ethically relevant information from the real world, which is empirically valid, and which is related to their in-game behavior.

Example: In The Detail (Rival Games, 2014), players face a dilemma, where they can either (a) rescue a girl, probably a sex slave, and arrest the gang member, who is holding her captive, or 
(b) ignore the apparent injustice to receive a case-related clue from the gangster. At the end of the episode, players are reminded of their decision, e.g., "You rescued the young lady from Santana's house", followed by this information: "It has been estimated that there are over 100,000 underaged victims involved in the sex trade within the United States each year. Runaway and homeless youth are especially targeted by traffickers."

Evaluation: Real-world facts may help to deepen empathy through a game (LO1), but probably only when authentic, positively-framed individuals are portrayed as victims of unethical behavior. This mechanism may foster reflection among players about important aspects that they have neglected in their in-game behavior, thereby expanding the scope of ethically relevant aspects, which people may be sensitized towards in future real-world situations (LO2). The mechanism could be used to sensitize players for biases (LO3): Placed in the dilemma featured above, players may experience a bias to obtain the case-related clue from the gangster, due to the pressure to make an immediate decision, and their game-related goal of getting their case solved - two factors, which often lead to moral blindness (Bazerman \& Tenbrunsel, 2011). Players who give into this bias, may regret their decision, once confronted with the realization, how many adolescents face sex crimes, and become wearier of relevant biases in the future.

\section{Contrasting with Other Players' Decisions}

The decisions, which players make, are recorded, and compared with the decisions of other players, at the end of a game (sequence).

Example: At the end of each episode of Life Is Strange (Dontnod, 2015), players find an overview of the different decisions, which they have made, and some of outcomes, which they have experienced. In addition, they receive information on which percentage of other players made 
the same decisions, and which percentage of other players made other decisions, and reached alternative results.

Evaluation: In games, where players may overlook options for interaction, this mechanism might help to make them aware of what else they could have done. In Life is Strange, some outcomes are more difficult to achieve than others, e.g., convincing a drug dealer to disclose his list of customers. Where players haven't found such a solution, which is ethically more favorable than the alternative (coercing the drug dealer to give you the list with a gun in his face), the information that others have found a peaceful solution may motivate players to retry. Thus, comparisons with the decisions and achievements of other players might motivate players to be more principled in their game actions, or give them a good feeling, of having behaved in a way, which they find to be morally superior (LO2). Potentially, this mechanism can also foster empathic concern, by getting players to think about why others may have behaved differently than them, e.g., in deciding about an ethical dilemma (LO1). Where players were misled through their biases, e.g., a narrow goal focus ("the main thing is I get that list"), the success of other players might cause them to question their own thinking (LO3).

\section{Value Explicitation}

Players are informed, to what extent they honored certain values through their game decisions, without these evaluations having consequences in the game concerning player's future options. Relevant evaluations can be articulated by NPCs, visualized through avatar appearance, won by reading newspaper articles about player decisions, etc. After-game consequences may fall into this category, e.g., when there are different stories told at the end of a game, depending on the player's moral behavior. 
Example: In the action-adventure game Dishonored 2 (Arkane, 2016), players may choose to reclaim their kingdom from an evil empress in a merciful, vengeful, or merciless manner. Merciful players avoid killing anyone, vengeful players only kill enemy soldiers, and merciless players even kill civilians, e.g., servants now working for the empress. The path players choose does not have in-game consequences, e.g., in terms of alliances or options. Players receive evaluative feedback via NPCs, who may praise or condemn their acts morally. At the end of each level, their actions are also scored on a scale from merciful to merciless. Finally, whether they have behaved in a virtuous or despicable way throughout the game, determines the final story that is told, once they have defeated the empress.

Evaluation: Value explicitation can come in many ways. Where empathy is induced with the victims of unethical behavior, e.g., through exposure to victims, or dialogues with in-game friends of the player, empathic sensitivity may be fostered (LO1). Where player decisions are evaluated morally, e.g., as unfair, or honorable, players may connect the relevant values and principles with game-related themes more quickly in the future, e.g., when thinking of what virtues or vices to value or despise in a political leader (LO2).

\section{Ironic Feedback}

Players' actions are evaluated in satirical ways, e.g., with exaggerated praise, selfcontradictory compliments, unsuitable awards, or ironic comparisons.

Example: Harpooned (Conor O'Kane, 2008): As "researchers", players hunt and kill whales. Successful missions yield outcomes such as "320 cans of pet food [...] and 1 research paper." (Flanagan \& Nissenbaum 2014, 64). 
Evaluation: Irony can be understood as a technique of communication, whereby people express an evaluation, which stands in contrast with the object of evaluation. Often, irony is used in satirical performances (e.g., movies, shows) to evaluate the actions of a person or organization in ways, which aren't perceived as overly serious and hurtful, but which destabilize incongruent assumptions. Irony can be used to deliver any kind of feedback related to MS via video games. A player, who has behaved selfishly could be humored as a "real team-player", thereby potentially arousing empathy with the rest of the team (LO1), and emphasizing the value of collaboration and mutual support (LO2) - if the irony is understood. Where players fall prey to biases, e.g., only thinking of short-term results, ironic feedback can sensitize them for their biases in a humorous way (LO3).

\section{Reputation Systems}

Players' actions have effects on how NPCs deal with them in future interactions. Effects can be immediate or delayed. Actions are thus rewarded / punished via their significance for different groups or individuals.

Example: PeaceMaker (ImpactGames 2007): In this simulation of the Israeli-Palestinian conflict, player decisions effect the attitudes of different social groups (Hamas, Israeli Settlers, UN, etc.), which are visualized through a polling instrument. High, balanced approval ratings of all groups are needed to win the game.

Evaluation: Reputation systems provide players with multi-perspective feedback on their game decisions. They can thereby motivate players to investigate and consider the interests of different parties more thoroughly (if a good reputation is helpful/necessary for in-game progression), and inform players about how different target groups or individuals may perceive 
their actions. Therefore, they are prone to foster empathic concern, even for members of large groups of people (LO1). Reputation systems could help to make players aware of their biases, e.g., if they generally tend to (implicitly) favor certain people or groups (LO3). However, reputation systems may also encourage players to take sides. They don't necessarily promote attention to moral values and principles, but could focus one's attention on the goals and strategic objectives of one's preferred group (LO2). Thus, without additional game mechanisms, reputation systems will not necessarily promote MS, and could even encourage the formation of stereotypes and attitudes that legitimize immoral behavior (moral disengagement).

\section{Discussion}

In this work, we have concentrated on the best possible outcomes of the game mechanisms, i.e., when they have been carefully crafted for learning purposes. In Table 1, we have marked those game mechanisms with a "+", which can probably contribute to the relevant learning outcome solitarily, i.e., without combining them with other game mechanisms. A " $(+)$ " signifies that we expect the game mechanism sensitize players morally, but only in combination with additional game mechanism(s). We frequently suggest that feedback is necessary to achieve positive results, corresponding with Hattie's (2009) finding that feedback is one of the most powerful forces of learning. A " 0 " marks a game mechanism, which we expect to be neutral. A "(-) " indicates that a game mechanism may conflict with a learning outcome, and that such a negative impact can only be avoided through its combination with a corrective game mechanism.

In summary, our study suggests that all 20 game mechanisms could promote the development of MS in one way or another. To optimally develop MS, we propose that different game mechanisms should be combined in ways, which maximize learning towards all learning 
outcomes, and which reduce the risks of single game mechanisms to achieve negative effects. Moreover, we would like to stress that this article cannot summarize all the relevant findings concerning the achievement of the three learning outcomes. Many factors, which haven't been pronounced here, will impact whether and how the presented game mechanisms can facilitate the development of MS. Many concern general quality factors of training interventions. For instance, to develop empathic concern for specific groups, these groups should be represented positively, ideally through authentic, representative characters (Martens, 1998). Other factors concern the nature of moral sensitivity. For example, the accessibility of moral schemas (principles, values, etc.) probably varies, depending on how well individuals understand different contexts, and how strongly they have been (de-)sensitized to moral features of these contexts. A teacher who is aware of ethically relevant features of teaching, may be unable to discern the ethical features of advertisement, and may not even relate those of her ethical standards to advertisement, which may be equally relevant (e.g., truthfulness). This implies that a video game, which trains MS in the domain of financial management may have limited use for the MS-training of medical practitioners. Finally, game designers should consider the probably level of MS, which the target group of their game has probably already developed, e.g., in view of Hoffmans' stages of developing empathy and Lawrence Kohlberg's stages of developing moral judgment (see Gibbs, 2010, for example). 
Table 1

Overview of Game Mechanisms

\begin{tabular}{|c|c|c|c|}
\hline Mechanism & $\begin{array}{c}\text { Empathic Concern } \\
\text { for Relevant } \\
\text { Groups }\end{array}$ & $\begin{array}{c}\text { Alertness to } \\
\text { Values/Principles }\end{array}$ & $\begin{array}{c}\text { Awareness for } \\
\text { Vulnerability to } \\
\text { Biases }\end{array}$ \\
\hline 1. Victim Perspective & + & $(+)$ & 0 \\
\hline 2. Perpetrator Perspective & $(-)$ & $(+)$ & $(+)$ \\
\hline 3. Perspective Change & + & + & + \\
\hline 4. Prosocial Challenge & + & + & 0 \\
\hline 5. Negotiation & + & + & + \\
\hline 6. Investigation & $(+)$ & + & $(+)$ \\
\hline 7. Conflict Mediation & + & + & $(+)$ \\
\hline 8. Ethical Dilemmas & $(+)$ & + & $(-)$ \\
\hline 9. Egoistic Temptations & $(+)$ & + & $(-)$ \\
\hline 10. Deception & + & $(+)$ & + \\
\hline 11. Action under Pressure & $(-)$ & $(+)$ & $(+)$ \\
\hline 12. Modelling & $(+)$ & $(+)$ & $(+)$ \\
\hline 13. Guidance & + & + & + \\
\hline 14. Direct Consequences & $(+)$ & $(+)$ & $(+)$ \\
\hline 15. Delayed Consequences & $(+)$ & $(+)$ & $(+)$ \\
\hline 16. Real-World Facts & $(+)$ & + & $(+)$ \\
\hline 17. Peer Comparison & $(+)$ & + & $(+)$ \\
\hline 18. Value Explicitation & $(+)$ & + & 0 \\
\hline 19. Ironic Feedback & $(+)$ & $(+)$ & $(+)$ \\
\hline 20. Reputation Systems & $(+)$ & $(-)$ & $(-)$ \\
\hline
\end{tabular}

\section{References}

Batson, C., Polycarpou, M., Harmon-Jones, E., Imhoff, H., Mitchener, E., Bednar, L., Klein, T., \& Highberger; L. (1997): Empathy and Attitudes: Can Feeling for a Member of a 
Stigmatized Group Improve Feelings Toward the Group? Journal of Personality and Social Psychology, 72, 495-509. doi:10.1037/0022-3514.72.1.105

Bazerman, M., \& Banaji, M. (2004). The Social Psychology of Ordinary Ethical Failures. Social Justice Research, 17, 111-115. doi:10.1023/B:SORE.0000027544.56030.04

Bazerman, M. H., \& Tenbrunsel, A. E. (2011). Blind spots: Why we fail to do what's right and what to do about it. Princeton: University Press.

Belman, J., \& Flanagan, M. (2010). Designing games to foster empathy. Cognitive Technology, 14, 5-15.

Blum, L. (1991): Moral perception and particularity. Ethics, 101, 701-725.

Christen, M., Faller, F., Götz, U., \& Müller, C. (2013). Serious moral games. Analyzing and engaging moral values through video games. Institute for Design Research, Zurich University of Arts: Zurich. https://www.encyclog.com/_upl/files/SeriousMoralGames_English_final.pdf

Decety, J., \& Cowell, J. (2014). Friends or Foes: Is Empathy Necessary for Moral Behavior? Perspectives on Psychological Science, 9(5), 525-537. doi:10.1177/1745691614545130

Flanagan, M., \& Nissenbaum, H. (2014). Values at play in digital games. Cambridge: MIT Press.

Formosa, P., Ryan, M., \& Staines, D. (2016). Papers, Please and the systemic approach to engaging ethical expertise in video games. Ethics and Information Technology 18(3), 211-225. doi:10.1007/s10676-016-9407-z

Ganesh, S., van Schie, H., de Lange, F., Thompson, E., \& Wigboldus, D. (2011): How the human brain goes virtual: distinct cortical regions of the person-processing network are involved 
in self-identification with virtual agents. Cerebral Cortex, 22(7), 1577-1585. doi: 10.1093/cercor/bhr227

Gibbs, J. (2010). Moral development \& reality. Beyond the theories of Kohlberg and Hoffman, $2^{\text {nd }}$ edition. Boston: Pearson.

Greitemeyer, T., Agthe, M., Turner, R., \& Gschwendtner, C. (2012). Acting prosocially reduces retaliation: Effects of prosocial video games on aggressive behavior. European Journal of Social Psychology, 42, 235-242. doi:10.1002/ejsp.1837

Grizzard, M., Tamborini, R., Lewis, R., Wang, L., \& Prabhu, S. (2014). Being Bad in a Video Game Can Makes Us More Morally Sensitive. Cyberpsychology, Behavior, and Social Networking, 17(8), 499-504. doi:10.1089/cyber.2013.0658

Hattie, J. (2009). Visible learning: A synthesis of over 800 meta-analyses to achievement. London: Routledge.

Hoffman, M. (2000). Empathy and moral development: Implications for caring and justice. Cambridge: University Press.

Joeckel, S., Bowman, N., \& Dogruel, L. (2012). Gut or Game? The Influence of Moral Intuitions on Decisions in Video Games. Moral Psychology, 15, 460-485. doi:10.1080/15213269.2012.727218

Jones, T. (1991). Ethical decision making by individuals in organizations: an issuecontingent model. Academy of Management Review, 16(2), 366-395. doi:10.5465/AMR.1991.4278958 
Jordan, J. (2009). A social cognition framework for examining moral awareness in managers and academics. Journal of Business Ethics, 84(2), 237-258. doi:10.1007/s10551-0089706-3

Martens, J. (1998). Verhalten und Einstellungen ändern, 4th Edition. Hamburg: Windmühle.

Miller, A., Gordon, A., \& Buddie, A. (1999). Accounting for evil and cruelty: is to explain to condone? Personality and Social Psychology Review, 3, 254-268. doi:10.1207/s15327957pspr0303_8

Rest, J. (1986). Moral development: advances in research and theory. New York: Praeger.

Rosenberg, R., Baughman, S., \& Bailenson, J. (2013): Virtual superheroes: using superpowers in virtual reality to encourage prosocial behavior. PLoS ONE 8(1). doi: 10.1371/journal.pone.0055003

Ryan, M., Staines, D., \& Formosa, P. (2016). Four Lenses for Designing Morally Engaging Games. Proceedings of 1st International Joint Conference of DiGRA and FDG.

Samuelson, \& Zeckhauser, R. (1988). Status quo bias in decision making. Journal of Risk and Uncertainty, 1(1), 7-59. doi:10.1007/BF00055564

Schrier, K. (2015). EPIC: a framework for using video games in ethics education. Journal for Moral Education, 44(4), 393-424. doi:10.1080/03057240.2015.1095168

Small, D., Loewenstein, G., \& Slovic, P. (2007). Sympathy and callousness: the impact of deliberative thought on donations to identifiable and statistical victims. Organizational Behavior and Human Decision Processes, 102(2), 143-153. doi:10.1016/j.obhdp.2006.01.005 
Staines, D. (2010). Videogames and Moral Pedagogy: A Neo-Kohlbergian Approach in K. Schrier \& D. Gibson (Eds.), Ethics and Game Design (pp. 35-51). Hershey: IGI Global.

Stevenson, J. (2011). A framework for classification and criticism of ethical games, in K. Schrier \& D. Gibson (Eds.), Designing games for ethics (pp. 36-55). Hershey: IGI Global.

Tanner, C., \& Christen, M. (2014). Moral intelligence - A framework for understanding moral competences. In M. Christen, J. Fischer, M. Huppenbauer, C. Tanner, \& C. van Schaik (Eds.), Empirically informed ethics (pp. 119-136), Berlin: Springer.

Vandenberg, P., \& Uglietta, J. (2015). Cultivating moral sensitivity, in: D. Mower, P. Vandenberg, W. Robinson: Developing moral sensitivity (pp. 43-57). New York: Routledge.

Wouters, P., van Nimwegen, C., van Oostendorp, H., \& van der Spek, E. (2013). A metaanalysis of the cognitive and motivational effects of serious games. Journal of Educational Psychology, 105(2), 249-265. doi:10.1037/a0031311

\section{Game References}

Arkane Studios (2016). Dishonored 2. Microsoft Windows, PlayStation 4, Xbox One. Bethesda Softworks.

CD Project RED (2015). The Witcher 3: Wild Hunt. Microsoft Windows, PlayStation 4, Xbox One. Warner Bros. Interactive Entertainment, Bandai Namco Entertainment.

Daedalic Entertainment (2016). Silence. Microsoft Windows, OS X, Linux.

Dontnod Entertainment (2015). Life is Strange. Linux, Microsoft Windows, OS X, PlayStation 3, PlayStation 4, Xbox 360, Xbox One. Square Enix, Feral Interactive. 
Eidos Montréal (2011). Deus Ex: Human Revolution. Microsoft Windows, OS X,

PlayStation 3, Wii U, Xbox 360. Square Enix.

ImpactGames (2007). PeaceMaker. Mac OS X, Microsoft Windows.

Ion Storm Austin (2000). Deux Ex. Mac OS, Microsoft Windows, PlayStation 2,

PlayStation 3. Eidos Interactive.

Irrational Games (2005). SWAT 4. Microsoft Windows. Sierra Entertainment.

Lionhead Studios (2001). Black \& White. Mac OS, Microsoft Windows. Electronic Arts, Feral Interactive.

Molleindustria (2006). The McDonald's Video Game. Web, Adobe Flash download. http://www.mcvideo game.com

O’Kane, C. (2008). Harpooned. Microsoft Windows, OS X.

Pope, Lucas (2013). Papers, Please. A Dystopian Document Thriller. Microsoft Windows, OS X, Linux, iOS, PlayStation Vita. 3909.

Procedural Arts (2005). Façade. Windows, Mac OS.

Rival Games (2014). The Detail. iOS, Linux, Microsoft Windows, OS X.

Team Bondi (2011). L.A. Noire. PlayStation 3, Xbox 360, Microsoft Windows. Rockstar Games.

2K Games (2007). Bioshock. iOS, Mac OS, Microsoft Windows, PlayStation 3, PlayStation 4, Xbox One, Xbox 360. 


\section{Author Biographies}

Johannes Katsarov is a doctoral researcher at the Center for Ethics of the University of Zurich. He investigates needs, means, limits and justifications of ethics training for professionals in business, medicine, and career counseling, with a focus on strategies of game-based learning.

Markus Christen is a senior research fellow at the Institute of Biomedical Ethics and History of Medicine and managing director of the Digital Society Initiative of the University of Zurich. His research interests are empirical ethics, neuroethics, ethics and technology, Serious Moral Games and data analysis methodologies.

Ralf Mauerhofer is a founder and employee of the game design and game development company Koboldgames GmbH. His company is specialized in motivation design with the help of games. He teaches courses about game design at universities and schools like the University of Arts in Zurich or the School for Design Basel.

David Schmocker is a doctoral researcher at the Institute of Banking and Finance, University of Zurich. As a psychologist in the fields of banking and finance, his research interests are moral intelligence, behavioral ethics, and computer-assisted learning. More precisely, he focuses on the measurement and the training of moral sensitivity through serious moral games.

Carmen Tanner is Professor of Economic Psychology and director of the Center for Responsibility in Finance at the University of Zurich, as well as Professor of Economic Psychology and Leadership Ethics at the Zeppelin University. Her research interests are behavioral business ethics, ethical decision making, moral intelligence, ethical leadership, and organizational culture. 